\title{
A contribuição da gestão de design para a conscientização do consumo responsável como alternativa para 0 desenvolvimento sustentável
}

\author{
por Antonio Martiniano Fontoura, Camila de Cássia \\ das Dores Ogava e Eugenio Andrés Díaz Merino
}

\section{RESUMO}

Compreender e discutir a importância da contribuição da gestão de design nas mudanças culturais acerca do consumo, que deverão ocorrer na sociedade para que a mesma possa seguir por caminhos de desenvolvimento sustentável. Desta forma o estudo observou as ações do design como articulador do consumo, que passa de um consumo voltado para sobrevivência, chegando ao padrão de consumismo, ou seja, consumo exacerbado, que tem uma relação direta com o desgaste social e ambiental da atualidade. Após debater estes conteúdos, conclui-se que para que hajam mudanças na produção e no consumo, são necessárias profundas mudanças culturais na sociedade. Enfatiza-se, ainda, a condição comunicadora de valores que a gestão de design pode inserir nos produtos com o intuito de levar conceitos de conscientização à sociedade, de forma que a mesma possa, com o tempo, se adequar a essa nova realidade de desenvolvimento sustentável.

Palavras-chave gestão de design; consumo; sustentabilidade

\section{ABSTRACT}

Understand and discuss the importance of the contribution of design management in cultural changes regarding the consumption, due to occur in society so that it can follow a path of sustainable development.By the way, the study observed the actions of design as an articulator of consumption, which is a consumer facing survival, reaching the standard of consumerism, ie excessive consumption, which has a direct relationship with the social and environmental wear today. After discussing these contents, it is concluded that for there to be changes in production and consumption, if necessary makes profound cultural changes in society. Emphasis is also the condition communicator of values that design management can insert the products in order to bring awareness to concepts of society, so that it can adapt over time to this new reality of sustainable development.

Keywords design; design managment; consumption; sustainibility 


\section{Introdução}

A atividade do design esteve desde sua criação estreitamente ligada ao desenvolvimento das sociedades. 0 design começou a ser conhecido na revolução industrial onde surgiu a necessidade de desenvolver produtos em larga escala atendendo necessidades dos usuários, buscando soluções para os problemas cotidianos dos usuários através de produtos, os quais também deviam ser vendáveis em meio à dinâmica crescente de mercado. Desde a revolução industrial até a atualidade, a produção só fez aumentar devido ao constante desenvolvimento e aprimoramento das tecnologias (DIEESE, 2011). No decorrer deste processo, o design, que antes era visto como uma ferramenta técnica, passou a usar de sua capacidade projetual para imprimir nos objetos os sonhos e desejos dos consumidores contribuindo para com a alavancagem das vendas, que por sua vez, traz agravantes para com a sociedade de consumo.

No decorrer do século XX, grande parte das discussões sobre design, manteve seu escopo sobre questões estritamente visuais e técnicas, que nem sempre levaram em consideração as fortes ligações que o design mantinha com a constituição da sociedade de consumo (SNIKER, 2009, p.15).

Campbell (2001) reforça a idéia do aumento do consumo na sociedade ao declarar que nenhum homem moderno, independente de sua classe ou situação, pode dizer que não há nada que deseje possuir. Para Vieira e Staub (2010) a sociedade do capitalismo contemporâneo faz do prazer o objeto da vida, e do consumo uma ética.

Levando em consideração a participação do design na construção deste modelo econômico, baseado no consumo como forma de satisfazer desejos, fica clara sua responsabilidade no desgaste socioambiental provocado pelo grande crescimento da produção que consome recursos naturais e provoca o descarte não responsável dos produtos consumidos. 0 design vem percebendo seu papel neste novo cenário, Castro entende o designer como uma testemunha do seu tempo, que não somente tem o objetivo de projetar, desenvolver, mas "projeta nas coisas a sociedade em que vive e seus próprios anseios" (CASTR0, 2008, p. 68). Sendo assim, o design corrobora na construção da cultura material da sociedade, comunica suas transições, conquistas, interações e valores. Fontoura (2009) acredita que é através das atividades do design que o homem constrói a cultura material, e o uso destes produtos traz a interação com o meio, com os outros e consigo mesmo. Sob este ponto de vista o designer que, segundo Bonsiepe (2011), é um solucionador inteligente de problemas que tem na atualidade o desafio de contribuir com as mudanças que já estão acontecendo na busca por um desenvolvimento sustentável no planeta.

Este estudo tem a intenção de discutir como a gestão de design pode contribuir nesta transição de uma cultura de consumo exacerbado e irresponsável para uma cultura de consumo consciente, possibilitando à sociedade um desenvolver socialmente justo, ambientalmente correto e economicamente viável, além de culturalmente aceito. Ao destacar a gestão de design neste papel, o artigo pretende visualizar de forma 
sistêmica o conjunto de ferramentas estratégicas, táticas e operacionais que visam interferir no desenvolver desta cultura de projetos sustentáveis.

\section{Conceituação dos termos design e gestão de design}

\section{Design}

0 termo design vem sendo usado com cada vez mais freqüência pela sociedade, no entanto o entendimento de seu conceito acaba que pouco definido, visto que é um conceito em constante renovação de conhecimentos devido sua multidisciplinaridade e interdisciplinaridade.

Para o Conselho Internacional das Sociedades de Design Industrial (ICSID) o Design é definido como sendo uma atividade criativa que tem por finalidade estabelecer as qualidades multifacetadas de objetos, processos, serviços e seus sistemas, buscando compreender todo seu ciclo de vida, sendo assim o mesmo teria papel central de humanização inovadora de tecnologias e um fator importantíssimo no intercâmbio econômico e cultural. Para Bigal o design é uma "força produtiva" (BICAL, 2001, p. 27) capaz de mediar tecnologias e materiais e por outro lado desenha informações, dá forma e torna os múltiplos objetos uma "matriz geradora de múltiplos significados" (BIGAL, 2001, p. 27). Sob um ponto de vista mais técnico Baxter (2000) defende a idéia de que o design é um grande amontoado de idéias que acaba por traduzir-se em conceito com a intenção de melhorar os aspectos funcionais, ergonômicos e visuais dos produtos com o intuito de satisfazer as necessidades dos usuários. Para Löbach (2001) o design compreende a realização de uma idéia em forma de projetos ou modelos, tendo como resultado um produto passível de produção em série e com finalidade de resolver problemas que resultam necessidades humanas.

Flusser traz a mediação “(...) design significa aproximadamente aquele lugar em que arte e técnica (e, conseqüentemente, pensamentos, valorativo científico) caminham juntas, com pesos equivalentes, tornando possível uma nova forma de cultura" (FLUSSER, 2007, p. 183-184). Na concepção de Moura a atividade de design compreende "trabalhar com a intenção, com o cenário futuro, executando a concepção e o planejamento daquilo que virá a existir" (MOURA, 2009, p. 118). Ainda para Braga "O design tradicionalmente foi concebido como um processo de criação cujo fim é o bem-estar humano" (BRAGA, 2009, p. 02). A atividade do design permite uma dinâmica na busca de múltiplos conhecimentos na aplicação de soluções cada vez mais completas para suprir as necessidades, como afirma Damazio (2006) a atividade de design é passível de muitas interpretações diferentes entre si, mas todas concordam que o Design pressupõe uma atividade ligada a soluções de necessidades.

Essa capacidade do Design de integrar inúmeros conhecimentos para chegar a soluções inovadoras chama atenção para uma nova atuação onde o design passa 
também a fazer parte do gerenciamento de processos, recursos, sejam eles materiais, financeiros ou humanos, em empresas e corporações, sendo estas características usadas como ferramentas estratégicas de diferenciação e inovação no que diz respeito ao alcance de metas, objetivos e comunicação das mesmas.

\section{Gestão de design}

Neste cenário o design deixa de ser apenas projeto e passa a ser Gestão de Design, no livro A Gestão de Design como Estratégia Organizacional Martins e Merino (2008) afirmam que 0 design está passando a fazer parte do universo das organizações, vivenciando seus problemas, mercados, projetos, e estratégias de modo integrado, evitando ações isoladas, que podem gerar riscos e deficiências ao processo. 0 design parece estar abrangendo uma nova gama de conhecimentos e desempenhando outras funções dentro das organizações que não apenas desenvolver produtos ou serviços, ele vem agregando competências de gestão que segundo D'ajuz (2003) compreende o gerenciamento de recursos da organização com o fim de alcançar os objetivos estabelecidos, envolvem, portanto o planejamento, execução, controle de ações corretivas, direcionamento de pessoas para que se obtenham os resultados esperados. De acordo com Câmara et al.(2007) as responsabilidades da gestão também são as de conduzir as equipes em harmonia com as atividades, assim como administrar bons relacionamentos entre outros setores que não estão diretamente ligados ao projeto.

Niemeyer destaca três etapas do design na história, sua evolução de práticas e conhecimentos:

(...) ao longo do tempo o design tem sido entendido segundo três tipos distintos de prática e conhecimento. No primeiro o design é visto como atividade artística, em que é valorizado no profissional o seu compromisso com artífice, com a fruição do uso. No segundo entende-se que o design como um invento, um planejamento em que o designer tem compromisso prioritário com a produtividade do processo de fabricação e com a atualização tecnológica. Finalmente, no terceiro aparece o design como coordenação, onde o designer tem a função de integrar os aportes de diferentes especialistas, desde a especificação de matéria-prima, passando pela produção à utilização e ao destino final do produto. Neste caso a interdisciplinaridade é a tônica. (...) estes conceitos tanto se sucederam como coexistiram, criando uma tensão entre as diferentes tendências simultâneas (NIEMEYER, 2007, p. 24).

Para Mozota (2011) além de exercer papeis administrativos como a gestão de recursos de toda espécie a característica que diferencia a gestão de design é a capacidade de identificar e comunicar as diversas maneiras pelas quais o design pode contribuir para a valorização estratégica da empresa. 0 Centro Português de Design no livro Manual de Gestão de Design (1997) descreve ao menos duas funções da gestão de design que em se tratando do projeto em si tem a função de gerir os recursos humanos e materiais desde o nascimento do projeto até seu lançamento no mercado e em âmbito 
empresarial procurará criar um ambiente favorável para o desenvolvimento de novos produtos. Avendaño (2002), afirma que a Gestão de Design deve ter um ponto de vista ampliado, que vise ser integrador e interativo com todas as instâncias que conformam o processo projetual, e para isso o designer deve adequar seu discurso para a complexidade desta ação onde se faz necessário uma visão integral e global da intervenção desta ferramenta no processo criativo, oferecendo estratégias e políticas que busquem integrar empresa, fornecedores e consumidores. A partir da gestão o design tem a possibilidade de alcançar e unir os setores de uma empresa, possibilitando com isso que as ações dentro desta organização sejam tomadas de forma integrada garantindo uma maior efetividade dos resultados. Resultados estes que irão interferir diretamente na sociedade, seu consumo, seus valores e conseqüentemente sua cultura.

\section{Sociedade de consumo}

\section{Consumo}

Para compreensão do termo sociedade de consumo é importante o entendimento da palavra consumo. Segundo Gomes (2009) a palavra consumo tem sua origem na língua inglesa e francesa, a autora define consumo como uma tentativa de proporcionar o aumento do bem-estar do indivíduo e da coletividade, através do suprimento de suas necessidades por bens e serviços.

Na história da humanidade chama à atenção a importância dada ao consumo na Grécia antiga onde duas palavras e uma expressão estavam ligadas ao consumo, eram elas: a palavra dapanau, que significa consumo no sentido de esgotar, finalizar, saldar e dapánai palavra que traduz o consumo como gastar dinheiro, gasto, prodigalidade, e por fim a expressão pornéia estava ligada ao consumo e ao amor, seu significado é de um amor voraz, devorador, destruidor, que consome aqueles que dele comungam, a idéia de consumo e amor ainda aparecem ligadas até os dias atuais (SILVA, 2007). Ainda para o mesmo autor, a idéia do consumo como é conhecido hoje surge no período da Roma antiga com o advento da Roma Imperial, no final do período Republicano, onde surgem os primeiros grandes mercados, aonde as pessoas iam para ver e serem vistas, e neste momento histórico o homem romano era medido pelo que possuía.

\section{Sociedade de consumo}

Partindo deste ponto de vista, Betts (2004), afirma que a sociedade de consumo se caracteriza pelas relações de consumo e valores associados, que estaria condicionado a produção de bens e serviços, para 0 autor "o sucesso social e a felicidade pessoal são identificados pelo nível de consumo que o individuo tem" (BETTS, 2004, p. 67), para Baudrillard (2008), a sociedade de consumo está ligada a princípios democráticos 
igualitários, que se sustentam sobre o mito da abundância e do bem estar, para ele a sociedade de consumo precisa de seus objetos para existir. Corroborando com estas afirmações, Alcantara (2007), faz entender que a sociedade de consumo tal como é conhecida atualmente teve sua fomentação com a Revolução Industrial, onde com 0 advento das máquinas e a produção de bens de consumo em alta escala, passou-se a estimular os trabalhadores a serem também consumidores. Segundo Betts (2004), o consumidor elevado ao status de cidadão, passa a ter como ideal de vida sua potência de consumo. Desde a revolução Industrial o conceito de consumo está associado ao suprimento de necessidades que foram se transformando com o passar do tempo 0 que antes era simplesmente sobrevivência passou pelos níveis de diversão, entretenimento e no século XXI, o indivíduo passa a buscar no consumo a experiência, naquilo que diz respeito ao objeto e/ou serviço, indivíduo e sociedade. Castro relata:

Quando os bens de consumo são investigados, sob um ponto de vista antropológico, nota-se que os objetos construídos por um determinado grupo social dizem muito a respeito de sua cultura. 0 conjunto de artefatos produzidos e utilizados por um determinado grupo social é chamado, portanto, de sua cultura material.

Mas por que objetos ou artefatos podem ser alçados à condição de narradores da história sócio-cultural de um grupo? Simplesmente, porque neles são embutidos valores simbólicos, carregados de significados. Consumimos bens simbólicos. Aquilo que eu compro me aproxima ou me distancia de outras pessoas. 0 carro que dirijo a roupa que visto ou o livro que leio diz muito a meu respeito (CASTRO, 2008, p. 64).

LYRA (2001) coloca que o importante é o fato de possuir a mercadoria e muito mais ainda o que ela simboliza o que torna os indivíduos inseridos ou não em um grupo social. A autora ainda destaca que aceitação deste discurso por uma grande parte da população sem condições objetivas de consumir o que lhes é proposto é legítima, pois os envolvidos buscam uma realização pessoal, através da posse de bens almejados pelas elites e pelos demais membros da mesma sociedade. Apesar do consumo nunca ter possuído tanta significação, como na sociedade contemporânea, ele é um dos aspectos constituintes da cultura contemporânea. No entanto o consumo, quando exagerado, transforma-se em consumismo (ARRUDA e LANDIM, 2009). Supervalorizar a inegável hegemonia da ideologia do consumo pode levar a que se perca de vista os demais problemas de nossa sociedade, por exemplo, deixar de entender, que somente existe consumo pelo efeito da atual grande produção de mercadorias.

É visto que a literatura sobre o consumo é vasta e atrelada a diferentes áreas de estudo, pois parece ficar claro seu impacto sobre os seres humanos e suas relações com o meio onde vive, com seu semelhante e sua cultura. As relações do ser humano com seu meio têm sofrido mudanças de cunho ambiental e social, onde o consumo tem uma parcela notável de responsabilidade, para que a sociedade mude os rumos de seu desenvolvimento serão necessárias mudanças de comportamentos por um desenvolvimento mais responsável e sustentável. 


\section{Sustentabilidade}

Fomentar mudanças no conceito de consumo da sociedade com a intenção de alterar os rumos da mesma em busca de um sistema sustentável é um desafio. Mas o entendimento deste conceito de sustentabilidade é sem dúvidas o primeiro passo para alcançar outros grandes objetivos. A palavra sustentabilidade vem do latim sustentare tem por definição suster, suportar, capacidade de garantir continuidade e perenidade (CALLADO e FENSTERSIFER, 2009).

0 conceito de sustentabilidade começou a ganhar força em 1987 com Relatório Brundtland, intitulado Nosso futuro Comum onde a Organização das Nações Unidas (ONU) assumiu o papel de debater com maior intensidade e propor uma mobilização mundial para o desenvolvimento sustentável, neste relatório o termo sustentabilidade foi definido como, atender às necessidades do presente sem comprometer a possibilidade de as gerações futuras atenderem às suas necessidades. Para Moraes Filho (2009), sustentabilidade está atrelado com o uso racional dos recursos da natureza, o respeito à capacidade regenerativa dos ecossistemas e 0 compromisso com as gerações futuras. Savitz e Weber (2007) afirmam que sustentabilidade, é o respeito à interdependência dos seres vivos entre si e em relação ao meio ambiente. 0 termo sustentabilidade se refere a uma mudança sistêmica dos atuais modelos de produção e consumo, em busca do equilíbrio entre fatores ambientais, sociais e econômicos, visando garantir a permanência presente e futura dos recursos do planeta. Para Sanchs (1993) é necessário que se compreenda a sustentabilidade ao menos por cinco dimensões para um entendimento mais completo sobre seu significado, sendo elas:

- sustentabilidade social: que melhora os direitos e as condições de vida das populações e diminui distâncias entre os padrões de vida dos grupos sociais;

- sustentabilidade econômica: viabiliza a alocação e a gestão eficiente dos recursos, avaliada muito mais sob critérios macro-sociais, e por fluxos regulares de investimentos públicos e privados;

- sustentabilidade ecológica: envolve medidas para reduzir o consumo de recursos e a produção de resíduos, intensificarem as pesquisas e a introdução de tecnologias limpas e poupadoras de recursos e para definir regras que permitam uma adequada proteção ambiental;

- sustentabilidade espacial: contempla uma configuração mais equilibrada das questões rural e urbana e uma melhor distribuição do território, envolvendo, entre outras preocupações, a ocupação em massa das áreas metropolitanas;

- sustentabilidade cultural: busca concepções originárias de dentro de cada cultura para o desenvolvimento, que respeitem as peculiaridades de cada ecossistema, de cada cultura e de cada local.

Para este estudo será considerada a sustentabilidade este conjunto interdependente entre vários elementos da sociedade por ser uma visão mais abrangente de 
todos os fatores que compreendem a continuidade do planeta e por estar diretamente ligada aos demais conceitos até então discutidos.

\section{Discussão}

É com intensidade que se tem discutido sobre o tema sustentabilidade nos últimos tempos, a busca é constante por alternativas que possibilitem que este conceito seja inserido definitivamente na sociedade. Manzini e Vezzoli colocam que "a perspectiva da sustentabilidade põe em discussão nosso atual modelo de desenvolvimento" (MANZINI e VEZZOLI, 2008, p. 31). Como já foi citado neste artigo, foi no relatório intitulado Nosso Futuro Comum em 1987 que o desenvolvimento sustentável começou a ganhar força, vindo a ser reforçado apenas em 1992, quando foi realizado na cidade do Rio de Janeiro (Brasil) a Conferência das Nações Unidas sobre Meio Ambiente e Desenvolvimento, que ficou conhecida como Eco-92 do qual resultou em um documento político chamado Agenda 21, que segundo Câmara "é considerada o marco definitivo para a inclusão do conceito de desenvolvimento sustentável nas políticas governamentais" (CÂMARA, 2009, p. 81).

Também foi a Agenda 21 responsável por inserir 0 debate sobre 0 consumo nas questões sociais e ambientais que antes estavam mais voltadas a produção (CLARK, 2007). De acordo com Giacomini Filho (2008), o produto, tão valioso nas relações de consumo, seria apenas o resultado de uma cadeia onde se envolvem inúmeros processos, sejam eles industriais, de infra-estrutura, de pessoas e muitos recursos naturais, para citar alguns, a conseqüência desta cadeia estendida, de fato, é o que faz do consumismo algo tão catastrófico ao meio ambiente. Mas é necessário destacar que se por um lado o consumo tem sido colocado como vilão da sociedade contemporânea por outro "sem o consumo, a produção não existiria, provocando 0 desequilíbrio do sistema (falta de emprego)" (MORAES FILHO, 2009, p. 02).

$\mathrm{Na}$ tentativa de se contornar esta situação ambígua do consumo chegou-se ao consenso de que o melhor consumo é aquele que o individuo faz de forma consciente, que segundo o Instituto Akatu significa:

Consideramos aqui "consumo consciente" como sendo o ato ou decisão de consumo (compra ou uso de serviços ou de bens industriais ou naturais) praticado por um individuo (uma pessoa física) levando em conta o equilíbrio entre sua satisfação pessoal, as possibilidades ambientais e os efeitos sociais de sua decisão. Ou seja, "consumo consciente" não deve aqui ser confundido com "não consumo" ou com o consumo de determinados produtos/serviços ou dentro de determinados padrões/quantidades. 0 que define a consciência no consumo não são parâmetros rígidos ou "receitas prontas", mas sim a reflexão consciente e abrangente do consumidor ao realizar suas escolhas. Assim, as práticas resultantes do "consumo consciente" podem ser diferentes, para diferentes contextos e consumidores (AKATU, 2005, p. 12). 
Sabendo que o consumo consciente (cabe dizer que para o estudo este consumo diz respeito tanto a pessoa física como a pessoa jurídica) é uma das formas que a sociedade tem para seguir por um desenvolvimento sustentável, cabe a este estudo questionar como a gestão de design poderá contribuir para esta transição, de uma cultura de consumo excessivo para uma cultura de consumo consciente?

Considerando que a criação e a produção de bens de consumo e, portanto de sonhos e desejos e estilos de vida, estão diretamente ligados a atividades do design (CASTRO, 2008), parece difícil acreditar que a própria atividade consiga mudar seus rumos de incentivadores do consumo para motivadores de consumos responsáveis e conscientes, no entanto, também é neste ponto que o design volta as suas raízes de solucionador de necessidades humanas, e se volta com todos os seus conhecimentos e evoluções para esta necessidade crescente e pujante da sociedade contemporânea. De acordo com Fachinetto, Macedo e Nascimento, "a função do designer pode ser compreendida como aquela que, ligando o que é possível tecnicamente/tecnologicamente ao que é ecologicamente necessário", faz surgir novas propostas que sejam apreciáveis tanto social como culturalmente (FACHINETTO, MACEDO e NASCIMENTO, 2006, p. 02).

Sendo assim, o designer tem a possibilidade de desenvolver seus projetos já visando minimizar os impactos do mesmo, principalmente de forma ambiental, usando materiais de fontes renováveis, duráveis, passíveis de reciclagem, reutilização, redução de materiais, produtos multifuncionais, componentes que possam ser facilmente substituídos (evitando o descarte do conjunto inteiro), simplificação do produto e da montagem, diminuição da embalagem, redução do gasto energético para a produção, porque para Manzini e Vezzoli, "os limites ambientais são testemunhas de que já não é mais possível conceber qualquer atividade de design sem confrontá-la com o conjunto das relações que durante o seu ciclo de vida, o produto vai ter no meio ambiente" (MANZINI e VEZZOLI, 2008, p. 99) e complementam que um designer que faça uso de uma abordagem sistêmica terá a possibilidade de visualizar com mais facilidade os impactos ambientais dos produtos, a fim de reduzi-los com eficácia, sem, portanto se limitar a deslocar estes impactos de uma fase para outra do ciclo de vida do mesmo. Para que essa visão sistêmica se estenda por todos os processos de desenvolvimento, produção, distribuição e comunicação dos produtos se fazem necessárias inserções destes conceitos e práticas dentro de outros níveis do processo produtivo de uma organização, onde normalmente o designer não terá a possibilidade de intervir visto que suas preocupações e ocupações estão em função do projeto do produto.

Para que todo o processo do projeto se dê de forma responsável se faz necessária outra atividade que esteja intimamente ligada ao projeto e suas conceituações quanto aos demais departamentos desta organização, neste cenário a gestão de design pode desempenhar com eficiência este papel, visto que suas atividades estão ligadas ao ato de gerir os recursos (de toda ordem), além de incentivar ligações entre o design e outros setores da empresa, com intuito de promover ações estratégicas, táticas e operacionais, visando diminuir o máximo de problemas de um projeto, desde a concepção até o lançamento. 
A gestão de design dentro dos níveis estratégicos contribui para as tomadas de decisão da empresa em relação ao desenvolvimento de estratégias de atuação e desenvolvimento em longo prazo tendo vista a missão e a visão da mesma. Portanto se a corporação tem como objetivo uma postura pró ativa em relação ao desenvolvimento sustentável, cabe à gestão de design propiciar estratégias de design que possibilitem o crescimento, competitividade, diferenciação e inovação desta empresa com base nestes valores, pois de acordo com Leite:

Tentar adivinhar que produtos e processos o futuro exigirá é um exercício fútil. Mas é possivel decidir que idéia se quer ver como realidade no futuro $e$ construir uma empresa diferente baseada nesta idéia. Fazer o futuro acontecer significa também criar uma empresa diferente (LEITE, 2009, p. 278).

Assim também em um nível tático a gestão de design pode cooperar no controle de ações para que as metas desta empresa nos projetos de design possam ser atingidas, neste momento a gestão de design atua juntamente com outros níveis gerenciais podendo ajudar no controle das atividades operacionais, fica a cargo deste nível, portanto compreender o planejamento, a implantação e o monitoramento das atividades (técnica e financeiramente) do projeto, que podem reduzir os riscos e minimizar as incertezas no sentido de viabilizar as estratégias da empresa (FUJITA, KEIL, HELLMEISTER, CHAVES e RAZERA, 2010).

Ao considerar o nível operacional, "as atividades de gestão de design são de caráter pontual", ou seja, a mesma se concentra nas atividades técnicas do projeto de design, segundo o Manual de Gestão de Design (1997, p. 32).

Tendo em vista 0 amparo e acompanhamento da gestão de design em todos os níveis de processamentos pelos quais passa o projeto o mesmo deverá chegar ao mercado o mais carregado possível de valores responsáveis, visto que todo seu processo foi pensado e realizado tendo como base os conceitos sustentáveis, desde sua concepção até seu descarte. Esta cadeia de acontecimentos responsáveis por trás do produto deverá chegar ao mercado, para Albuquerque e Oliveira (2009) as empresas que investem em uma imagem mais consciente e, com produtos e processos mais responsáveis são mais respeitadas, têm mais simpatia do publico e crescem mais, "produtos criados para durar mais e preparados e montados com mais cuidado terão obviamente que custar mais" (PAPANEK, 1995, p. 51) para que isso aconteça se faz necessário que o produto comunique ao consumidor seus valores e suas vantagens, e influencie de forma correta o mesmo.

Novamente Manzini e Vezzoli (2008), concordam que devem ser propostas políticas ambientais orientadas ao produto, que tendam a agregar funções comunicadoras (feedback) ao mesmo, o que significa promover gerações de produtos capazes de comunicar/informar ao usuário suas implicações ambientais, e possivelmente sociais. Os autores ainda levantam o fato de que fazer com que o consumidor se atente a estes fatores ainda é o mais difícil e que as mudanças para a sustentabilidade poderão ser vistas como um processo de adaptação da aprendizagem, logo a comunicação se faz um fator determinante para essa transição, e para que 
a inversão de valores e as mudanças da cultura da sociedade contemporânea se construam e se estabeleçam.

É neste ponto do projeto onde deve haver uma concentração de esforços da gestão de design, a fim de desenvolver aspectos altamente comunicadores nos produtos com intuito de garantir a transmissão dos conceitos responsáveis por trás do produto para o consumidor. Este estudo concorda que o processo de mudanças comportamentais em relação ao consumo que visa o desenvolvimento sustentável deve começar pelas organizações, e que a gestão de design deve exercer um papel importante considerando seus atributos sistêmicos dentro da mesma, principalmente no que diz respeito à comunicação de valores, tendo o cuidado de conduzir os projetos com responsabilidade e consciência em todas as suas instancias, assumindo responsabilidades com o ciclo de influências dos produtos para um consumo consciente na sociedade (figura 01), onde a mesma esteja ciente do impacto do comportamento consumista, e partindo dessa conscientização, possa promover e facilitar a transição da cultura de consumo excessivo para uma cultura de consumo consciente.

\section{CICLO DE INFLUÊNCIA PARA COM O CONSUMO CONSCIENTE}

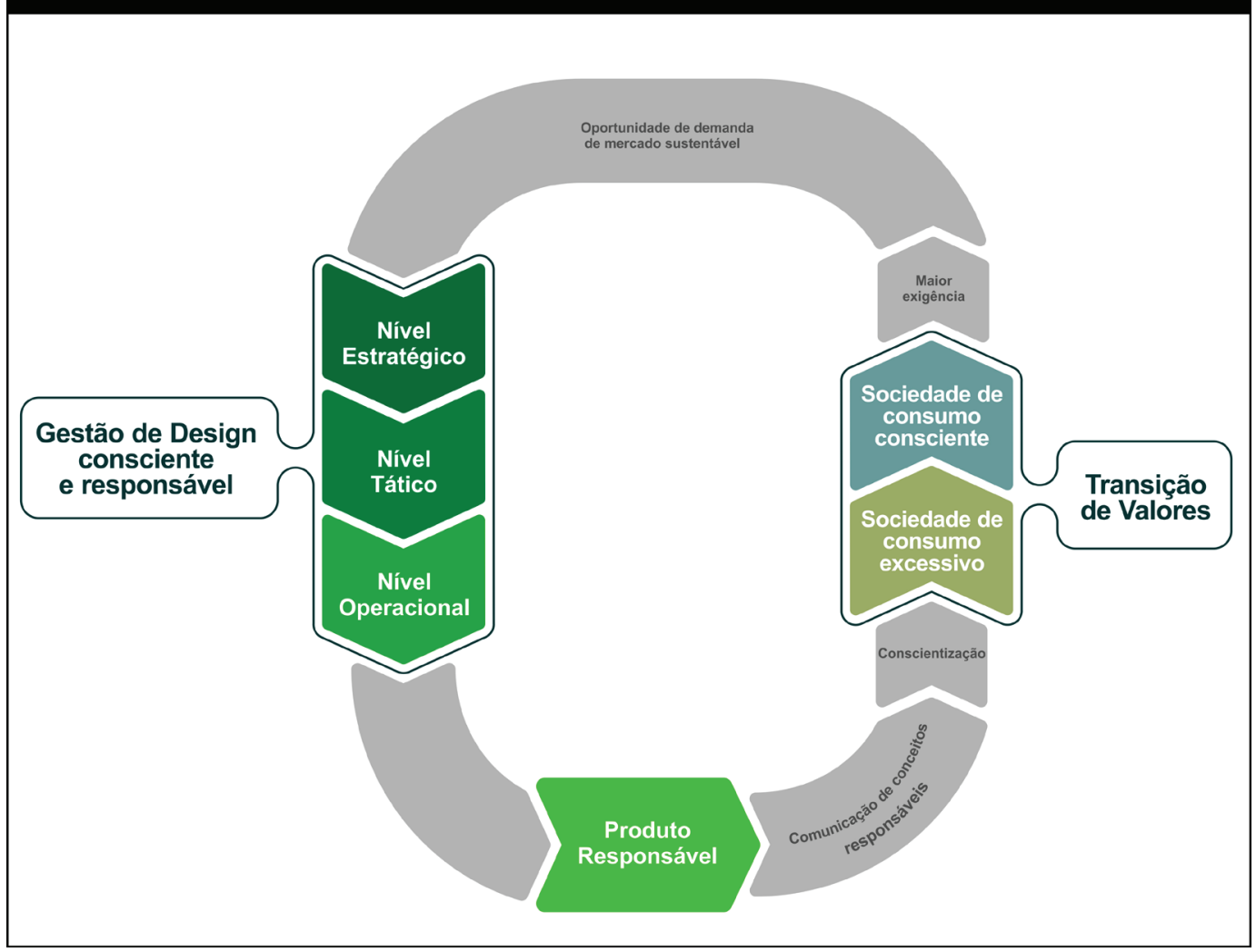

Figura 1. Ilustração do fluxo de influência da Cestão de Design para o consumo consciente Fonte: desenvolvido pela autora

A imagem acima demonstra o ciclo de influência gerada pela conscientização que parte da gestão de design em nível estratégico, onde as decisões voltadas ao 
desenvolvimento sustentável são tomadas em longo prazo, que passa pelo nível tático onde as informações geradas pelas estratégias são gerenciadas e chegam ao nível operacional onde são realizadas, dando origem a um produto. 0 produto que sai deste processo possui uma carga de valores responsáveis, que foi trabalhado pela gestão de design para comunicar os mesmos com a sociedade consumido$\mathrm{ra}$, com a intenção de gerar conscientização e gradativamente uma transição de valores que deverá ocorrer quando o consumidor estiver ciente dos impactos do seu consumo. A sociedade consciente passará a ser mais exigente em relação aos produtos, e, portanto gerará uma demanda de mercado a empresas que estejam atuando com estas estratégias de sustentabilidade, o que forçará também que outras empresas se adéqüem a esta situação.

\section{Conclusão}

Vê-se a inerente necessidade de mudanças nos padrões de consumo da sociedade para que a mesma tenha condições de se adequar ao desenvolvimento sustentável, no entanto, a maior parte dos produtos/serviços consumidos ainda comunica de forma explicita os excessos, a obsolescência, o descarte irresponsável, formando uma cultura consumista que busca no consumo a realização pessoal, o status e a diferenciação sem ao menos se dar conta dos impactos causados por essas ações desmedidas. Para Gomes (2009) o consumo exagerado tem como tendência causar patologias sociais como ansiedade e descontentamento, a autora cita ainda Jackson para dizer quais os benefícios de uma sociedade que preza pelo consumo consciente, e ele afirma que "a diminuição do consumo e da importância social dada ao consumir pode trazer um duplo dividendo: a redução de recursos materiais empregados e o aumento de bem estar individual e coletivo" (JACKSON, 2005 apud GOMES, 2009, p. 43).

Manzini e Vezzoli corroboram com esta afirmativa:

A transição por escolha só poderá ter lugar se um grande número de pessoas reconhecer, na própria transição, uma oportunidade para melhorar o seu grau de bem estar. Mas, para que tudo possa surtir efeito no quadro da redução dos consumos matérias que, todavia, vai ser necessária, é preciso que sejam transformados os juízos de valores e os critérios de qualidade que interpretam a idéia de bem estar. (MANZINI e VEZZOLI, 2008, p. 55)

Este estudo, através da discussão de diversos pontos de vista e da conceituação de termos relevantes sobre a cultura de consumo e a transição para uma cultura de consumo consciente, reconhece as contribuições da gestão de design neste período de mudanças de valores, tendo em vista o desenvolvimento sustentável. 0 mesmo compreendeu de forma clara que a gestão de design, contribui para a transição cultural do consumo, quando de forma estratégica insere valores sustentáveis e ações conscientes em todos os níveis dos projetos (estratégico, tático e 


\section{A contribuição da gestão de design para \\ a conscientização do consumo responsável como \\ alternativa para o desenvolvimento sustentável}

operacional), além disso, considerando o aspecto integrador da gestão de design é capaz de imprimir esses valores na identidade da empresa, favorece a percepção da mesma pelo mercado como consciente e responsável, gera-se com isso uma vantagem competitiva de diferenciação para as organizações que se atentarem rapidamente para esses valores.

Através desse estudo entendeu-se historicamente a responsabilidade do design no estímulo ao consumo, de igual forma pode-se constatar as condições do design aliado a sua vertente de gestão estratégica uma importante alternativa para a conscientização da sociedade sobre sua real situação atual e sobre os possiveis caminhos a serem seguidos, uma vez que o design é um importante registro do seu tempo e por sua vez um elemento cultural.

Outros estudos sobre este tema poderão mensurar de forma quantitativa e qualitativa a atuação da gestão de design nas organizações na busca por promover o desenvolvimento sustentável para a sociedade. 


\section{Referências}

> ALBUQUERQUE. José de Lima; OLIVEIRA, Célia Vicente de. Auditoria ambiental. In: ALBUQUERQUE, José de Lima (org.). Gestão Ambiental e Responsabilidade Social: conceitos, ferramentas e aplicações. São Paulo: Editora Atlas, 2009, p.260-272.

> ALCANTARA, Vânia. Sociedade de consumo e impactos ambientais. Disponível em: http://www2.ciashop.com.br/iesde/product.asp?template_id=74told_template_id=74atpartner_id=8atu=b2catutm_source=C00GLECtdept_id=300atpf_ $\mathrm{id}=14849$. . Acesso em: 11/06/11.

$>$ AKATU, Instituto. Consumidores conscientes: o que pensam e como agem. Disponível em: http://www.akatu.org.br/Content/Akatu/Arquivos/file/Publicacoes/8pesq_5-Internet-Final.pdf. Acesso em: 11/06/2011.

> AVENDAÑo, Luis Emiliano. Gestão do Design. Disponível em: avargas.com.br/ dezine/zine/003/avendano_003.htm. Acesso em: 26/09/2011.

> ARRUDA, Glória L. Rodríguez Correia de. LANDIM Paula da Cruz. Indústria, sustentabilidade e design. In. SILVA, Jofre; MOURA, Mônica; SANTOS, Aguinaldo dos (orgs.). Anais do $2^{\circ}$ Simpósio Brasileiro de Design Sustentável. São Paulo: Rede Brasil de Design Sustentável, 2009.

> BAXTER, M. Projeto de Produto. 2. ed.. São Paulo: Edgard Blücher, 2003.

> BETTS, Jaime Alberto. Sociedade de Consumo e Toxomania: Consumir ou não ser. Disponível em: http://www.appoa.com.br/revista.php?sec=3. Acesso em: 10/07/11.

> BICAL, Solange. 0 design e o desenho industrial. São Paulo: Annblume, 2001.

> BRAGA, Eduardo Cardoso. Em busca de um design ecocêntrico. In. SILVA, Jofre; MOURA, Mônica; SANTOS, Aguinaldo dos (orgs.). Anais do $2^{\circ}$ Simpósio Brasileiro de Design Sustentável. São Paulo: Rede Brasil de Design Sustentável, 2009.

$>$ CALLADO, Aldo Leonardo Cunha; FENSTERSEIFER, Jaime Evaldo. Indicadores de Sustentabilidade. In: ALBUQUERQUE, José de Lima (org.). Gestão Ambiental e Responsabilidade Social: conceitos, ferramentas e aplicações. São Paulo: Editora Atlas, 2009, p. 213-234.

> CÂMARA. Renata Paes de Barros. Desenvolvimento Sustentável. In: ALBUQUERQUE, José de Lima (org.). Gestão Ambiental e Responsabilidade Social: conceitos, ferramentas e aplicações. São Paulo: Editora Atlas, 2009, p.70-89.

> CÂMARA, Jairo José Drummond, Prof. Dr.; MONTEIRO,Roberta C. Dias; OLIVEIRA, Williane Alves; MENDONÇA, Lílian Lima; BOTELHO, Róber Dias. A gestão do design na concepção de novos produtos e a diferenciação mercadológica. Disponível em: fido.palermo.edu/servicios_dyc/encuentro2007/02_auspicios_publicaciones/actas_diseno/articulos_pdf/A3115.pdf. Acesso em: 26/09/2011.

> CAMPBELL, C. A ética romântica e o espírito do consumismo moderno. Rio de Janeiro: Rocco, 2001.

> CASTRO, Gabriela Varanda. Design de interiores e consumo: a percepção dos aspectos sócio-ambientais em móveis e objetos decorativos. Dissertação (Mestrado 
em Artes e Design) - Pontifícia Universidade Católica do Rio de Janeiro, Rio de Janeiro, 2008. Orientador: Alfredo Jefferson de Oliveira. - 2008.

> CLARK, G. Evolution of the global sustainable consumption and production policy and the United Nations Environment Programme's (UNEP) supporting activities. Journal of Cleaner Production. v. 15, n. 6, 2007, p. 492-498.

> ICSID. Definição de Design. Disponível em: 〈http://www.icsid.org/〉. Acesso: 15/06/11.

> DAMAZIO, Vera. Org. Luiz Antonio I. Coelho. Design Método - Col. Tecnologias e Ciências Humanas. Rio de Janeiro: Ed. Novas Idéias, 2006.

> D’AJUZ, Maria Cristina Lima. Modelo de Gestão: diferencial competitivo ou uma grande incógnita?. Disponível em: http://www.perspectivas.com.br/art71.htm. Acesso em 26/09/2011.

> DIEESE, Departamento Intersindical de Estatísticas e Estudos Socioeconômicos. Desindustrialização: Conceito e a situação do Brasil. Disponível em: www.portal. mte.gov.br/data/files/.../dieese_nt100.pdf . Acesso em: 26/09/2011.

> FACHINETTO, Marina. MACEDO, Fernanda Busnardo NASCIMENTO, Marilzete Basso. Sustentabilidade como Requisito de Design. $7^{\circ}$ Congresso Brasileiro de Pesquisa e Desenvolvimento em Design. Paraná, 2006.

> FILHO, Rodolfo Araújo de Moraes. Sociedade e Meio Ambiente. In: ALBUQUERQUE, José de Lima (org.). Gestão Ambiental e Responsabilidade Social: Conceitos, ferramentas e aplicações. São Paulo: Editora Atlas, 2009, p. 01-26.

> FLUSSER, Vilém. 0 mundo codificado. São Paulo: Cosac Naify, 2007.

> FONTOURA, Antonio Martiniano; 0 construtivismo, a realidade objetiva social, a cultura material, a teoria dos objetos e o design. Disponivel em: http://abcdesign. com.br/por-assunto/teoria/o-construtivismo-a-realidade-objetiva-social/). Acesso: 10/06/11.

> FUJITA, Carolina Taeko; KEIL, Malis Maria Liebl; H ELLMEISTER, Victor; CHAVES, Liliane Iten; RAZERA, Dalton Luiz. Integração dos Níveis de Gestão do Design e de Design para a Sustentabilidade aplicada a Mobiliários. $9^{\circ}$ Congresso Brasileiro de Pesquisa e Desenvolvimento em Design, 2010. Disponível em: http://blogs.anhembi.br/congressodesign/anais/artigos/69805.pdf. Acesso em: 02/10/2011.

> GIL, Antônio Carlos, 1946 - Como elaborar projetos de pesquisa / Antônio Carlos Cil. - 3. ed. - São Paulo : Atlas, 1991.

> GIACOMINI, Filho, G. Meio Ambiente a Consumismo. São Paulo: Editora Senac. São Paulo; 2008

> GOMES, Liziane Regina. Educação através do Design no ensino fundamental público de Curitiba: Panorama e possibilidades. Dissertação como requisito parcial para obtenção do titulo de Mestre em Design. Universidade Federal do Paraná. Curitiba. 2009.

> KASSER, Tim. The high price of materialism. London: MIT Press, 2002. 


\section{A contribuição da gestão de design para \\ a conscientização do consumo responsável como \\ alternativa para o desenvolvimento sustentável}

> LEITE, Emanuel Ferreira. Ecoempreendedorismo e gestão ambiental. In: ALBUQUERQUE, José de Lima (org.). Gestão Ambiental e Responsabilidade Social: conceitos, ferramentas e aplicações. São Paulo: Editora Atlas, 2009, p. 274-299.

$>$ LÖBACH, B. Design Industrial - bases para a configuração dos produtos industriais. São Paulo: Edgard Blücher; 2001.

> LYRA, Renata Maldonado da Silva. Consumo, Comunicação e Cidadania. Ciberlegenda Número 6, 2001.< http://www.uff.br/mestcii/renata2.htm>Acesso em: 26/09/2011

> MARTINS, Rosane Fonseca de Freitas, MERINO Eugenio. A Gestão de Design como Estratégia Organizacional. Londrina: EDUEL, 2008.

> MOURA, Mônica (Org.). Faces do Design 2: ensaios sobre a arte, cultura visual, design gráfico e novas mídias. São Paulo: Rosari, 2009

> MOZOTA, Brigitte Borja de. Gestão de Design:usando o design para construir valor de marca e inovação corporativa. Porto Alegre: Bookman, 2011.

> NIEMEYER, Lucy. Design no Brasil: Origens e instalação. Rio de Janeiro: 2AB, 2007.

> PAPANEK, Victor. Arquitetura e Design: Ecologia e Ética. Lisboa: Editora Edições 70, 2007.

> SNIKER, Tomas Guner. 0 Diálogo entre o Design e a Arte na sociedade de consumo: do uso ao valor de seleção. Dissertação como requisito parcial para obtenção do titulo de Mestre. Escola de Comunicação e Artes, Universidade de São Paulo, 2009.

> SAVITZ, A. W.; WEBER, K. A empresa sustentável: o verdadeiro sucesso é o lucro com responsabilidade social e ambiental. Rio de Janeiro: Elsevier, 2007.

> SILVA, Gustavo de Castro. Imaginação, linguagem e consumo. Vol. 4, N. 10, 2007. http://revcom.portcom.intercom.org.br/index.php/comunicacaomidiaeconsumo/issue/view/359/showToc. Acesso em: 10/06/2011.

> SACHS, I. Estratégias de transição para o século XXI: desenvolvimento e meio ambiente. São Paulo: Studio Nobel, 1993.

> VIEIRA, Susana Medeiros; STAUDT, Leo Afonso. 0 Designer na Sociedade: Investigações Filosóficas Designer. $9^{\circ}$ Congresso Brasileiro de Pesquisa e Desenvolvimento em Design. 2010, Outubro, 13 e 16; Universidade Anhembi Morumbi, Brasil. 
Antonio Martiniano Fontoura, possui graduação em Desenho Industrial pela Pontifícia Universidade Católica do Paraná (1986), graduação em Esquema I Curso Superior de Formação de Professores pela Universidade Tecnológica Federal do Paraná (1992), mestrado em Educação pela Pontifícia Universidade Católica do Paraná (1997) e doutorado em Engenharia de Produção pela Universidade Federal de Santa Catarina (2002). Atualmente é professor no curso de Mestrado em Design da Universidade Federal do Paraná, professor adjunto da Pontifícia Universidade Católica do Paraná, coordenador adjunto do curso de desenho industrial da Pontifícia Universidade Católica do Paraná e prof. do ensino básico tec. tecnológico da Universidade Tecnológica Federal do Paraná. Tem experiência na área de Desenho Industrial, com ênfase em Ensino do Design, atuando principalmente nos seguintes temas: design, educação através do design, design de embalagem, embalagem e design e educação.

\section{fontoura.antonio@gmail.com}

Camila de Cássia das Dores Ogava, possui graduação em Desenho Industrial pela Faculdade de Ciencias e Tecnologia de Birigui (2009) e Especialista em Gestão de Design pela Universidade Federal de Santa Catarina (2011).Atualmente é aluna em nível de mestrado do Programa de Pós-graduação em Design e Expressão Gráfica na Universidade Federal de Santa Catarina (2012), atuando na linha de pesquisa de Cestão de Design, voltada para a aproximação do conceito para micro e pequenas empresas. Além disso, é Bolsista CNPQ pelo projeto Agente Local de Inovação no estado de Santa Catarina.

kmilakssia@hotmail.com

Eugenio Andrés Díaz Merino, possui graduação em Desenho Industrial pela Universidade Federal do Rio de Janeiro (1993), mestrado em Engenharia de Produção pela Universidade Federal de Santa Catarina (1996) e doutorado em Engenharia de Produção pela Universidade Federal de Santa Catarina (2000). Atualmente é professor associado II da Universidade Federal de Santa Catarina e coordena o Nucleo de Gestão de Design. Tem experiência na área de Design, com ênfase em Gestão de Design e na área de engenharia, especificamente com ergonomia, produto e processo. Participa dos programas de pós-graduaçao em Design e Engenharia de Produção ambos da UFSC. Faz parte do grupo de avaliadores do INEP/MEC e do Conselho Estadual de Educaçao de Santa Catarina na avaliação de cursos. É lider do grupo de pesquisa em gestao de design e pesquisador CNPq.

merino@cce.ufsc.br 